\title{
Regional differences in advanced gastric cancer: exploratory analyses of the AVAGAST placebo arm
}

\author{
Akira Sawaki ${ }^{1,18} \cdot$ Yasuhide Yamada $^{2} \cdot$ Kensei Yamaguchi $^{3,7} \cdot$ Tomohiro Nishina $^{4} \cdot$ Toshihiko Doi $^{5}$. \\ Taroh Satoh $^{6,19} \cdot{\text { Keisho } \text { Chin }^{7} \cdot \text { Narikazu Boku }^{8,2} \text { - Yasushi Omuro }}^{9}$ Yoshito Komatsu ${ }^{10}$ - Yasuo Hamamoto ${ }^{11}$. \\ Wasaburo Koizumi ${ }^{12,20}$ • Shigehira Saji ${ }^{13,21}$ • Manish A. Shah ${ }^{14}$ • Eric Van Cutsem ${ }^{15}$ - Yoon-Koo Kang ${ }^{16}$. \\ Junko Iwasaki $^{17}$ - Hiroshi Kuriki ${ }^{17}$ - Wataru Ohtsuka ${ }^{17}$ - Atsushi Ohtsu ${ }^{5}$
}

Received: 11 July 2017 / Accepted: 6 October 2017 / Published online: 20 October 2017

(c) The Author(s) 2017. This article is an open access publication

\begin{abstract}
Background AVAGAST was an international, randomized, placebo-controlled phase III study of chemotherapy with or without bevacizumab as first-line therapy for patients with advanced gastric cancer. We performed exploratory analyses to evaluate regional differences observed in the trial.

Methods Analyses were performed in the placebo plus chemotherapy arm (intention-to-treat population). Chemotherapy was cisplatin $80 \mathrm{mg} / \mathrm{m}^{2}$ for six cycles plus capecitabine $\left(1000 \mathrm{mg} / \mathrm{m}^{2}\right.$ orally bid days $\left.1-14\right)$ or 5 -fluorouracil $\left(800 \mathrm{mg} / \mathrm{m}^{2} /\right.$ day continuous IV infusion days $\left.1-5\right)$ every 3 weeks until disease progression or unacceptable toxicity. Results Overall, 387 patients were assigned to placebo plus chemotherapy (eastern Europe/South America, $n=118$; USA/western Europe, $n=81$; Korea/other Asia, $n=94$;
\end{abstract}

Akira Sawaki

sawaki@jk2.so-net.ne.jp

1 Aichi Cancer Center Hospital, Aichi, Japan

2 Present Address: National Cancer Center Hospital, Tokyo, Japan

3 Saitama Cancer Center Hospital, Saitama, Japan

4 Shikoku Cancer Center, Ehime, Japan

5 National Cancer Center Hospital East, Kashiwa, Japan

6 Faculty of Medicine, Kinki University Hospital, Osaka, Japan

7 Present Address: Cancer Institute Hospital of JFCR, Tokyo, Japan

8 Shizuoka Cancer Center, Shizuoka, Japan

9 Tokyo Metropolitan Cancer and Infectious Disease Center, Komagome Hospital, Tokyo, Japan

10 Hokkaido University Hospital, Sapporo, Japan

11 School of Medicine, Keio University, Tokyo, Japan
Japan, $n=94)$. At baseline, poor performance status, liver metastases, and larger tumors were most frequent in eastern Europe/South America and least frequent in Japan. Patients received subsequent chemotherapy after disease progression as follows: eastern Europe/South America (14\%); USA/western Europe (37\%); Korea/other Asia (61\%); and Japan (77\%). Hazard ratios for overall survival versus USA/ western Europe were 1.47 (95\% CI, 1.09-1.99) for eastern Europe/South America, 0.91 (95\% CI, 0.67-1.25) for Korea/ other Asia, and 0.87 (95\% CI, 0.64-1.19) for Japan.

Conclusions Regional differences in the healthcare environment may have contributed to the differences in overall survival observed in the AVAGAST study.

12 Kitasato University East Hospital, Kanagawa, Japan

13 International Medical Center, Saitama Medical University, Saitama, Japan

14 Weill Cornell Medical College/New York Hospital, New York, USA

15 University Hospitals Gasthuisberg, Leuven and KULeuven, Louvain, Belgium

16 Asan Medical Center, University of Ulsan, Seoul, South Korea

17 Chugai Pharmaceutical Co Ltd, Tokyo, Japan

18 Present Address: Department of Medical Oncology, School of Medicine, Fujita Health University, Toyoake, Aichi 470-1192, Japan

19 Osaka University Hospital, Osaka, Japan

20 Present Address: Kitasato University Hospital, Tokyo, Japan

21 Present Address: Fukushima Medical University, Fukushima, Japan 
Keywords Stomach neoplasms - Survival analysis · Geographic locations

\section{Introduction}

Gastric cancer is a heterogeneous disease, and its incidence shows wide variation among geographic regions. Although the global incidence of gastric cancer has decreased markedly over the past 40 years, almost 1 million new cases are estimated to have occurred in 2012 [1]. Gastric cancer remains highly prevalent in eastern Asia (mainly in China) and is also common in central and eastern Europe and in central and South America [1]. Western Europe and North America are considered low-risk regions [2], although there has been a steady increase in gastroesophageal junction carcinoma in these geographic regions since the 1970s [3].

AVAstin in GASTric cancer (AVAGAST) was an international, randomised, phase III study designed to compare the efficacy of bevacizumab plus standard chemotherapy versus placebo plus chemotherapy as first-line treatment for patients with advanced gastric cancer [4]. In the primary efficacy analysis, the addition of bevacizumab to chemotherapy significantly prolonged progression-free survival and improved overall response rate, but had no significant benefit on the primary study endpoint, overall survival [4]. Randomization in the AVAGAST trial was stratified by region (Asia Pacific, Europe, pan-America). In pre-planned subgroup analyses, it was evident that efficacy outcomes in both treatment arms varied markedly by region, with patients from the Asia-Pacific region showing no survival benefit from the addition of bevacizumab to chemotherapy, in contrast to patients from other regions [4]. Furthermore, patients from the Asia-Pacific region who received placebo plus chemotherapy had better outcomes than patients from other regions [4].

At the time of the study, regional differences in the prognosis of gastric cancer were one of the major clinical questions. The factors influencing observed differences in prognosis were considered to be either tumor biology or the healthcare environment. The effects of tumor biology on outcomes in the AVAGAST study have already been reported $[5,6]$, but the impact of the healthcare environment has not been studied. Therefore, we performed a set of exploratory analyses using data from the AVAGAST trial to examine the effect of regional differences in the healthcare environment on study outcomes by investigation of the use of secondline therapy and baseline characteristics. We analyzed data from the placebo group only to exclude the possible effects of bevacizumab. The cutoff date for the primary analysis was November 2009, after a median follow-up of approximately 10 months. The cutoff date for the present analysis was almost 4 years later at the time of trial completion in September 2013.

\section{Methods}

\section{Study design}

AVAGAST was a prospective, randomized, double-blind, placebo-controlled, phase III trial designed to evaluate the efficacy of adding bevacizumab to capecitabine plus cisplatin in the first-line treatment of patients with advanced gastric cancer. The design of AVAGAST has been described in full previously [4]. The protocol was approved at each participating site by an independent ethics committee or institutional review board. The trial was registered (ClinicalTrials.gov identifier: NCT00548548).

\section{Patients}

Patients with histologically confirmed, unresectable, locally advanced, or metastatic adenocarcinoma of the stomach or gastroesophageal junction who had received no previous treatment for metastatic gastric cancer were eligible. Patients could have measurable or non-measurable disease, provided that it was evaluable according to response evaluation criteria in solid tumors (version 1.0) [7]. (Neo)adjuvant chemotherapy was allowed if completed within 6 months before randomization, but previous platinum or anti-angiogenic therapy was not permitted.

\section{Randomization and treatment}

Patients were randomly assigned (1:1) to bevacizumab (Avastin) or placebo plus capecitabine or 5-fluorouracil in combination with cisplatin. Bevacizumab $7.5 \mathrm{mg} / \mathrm{kg}$ or placebo was administered as an intravenous infusion on day 1 , followed by cisplatin $80 \mathrm{mg} / \mathrm{m}^{2}$ as an intravenous infusion, then oral capecitabine $1000 \mathrm{mg} / \mathrm{m}^{2}$ twice daily on days $1-14$ every 3 weeks. Cisplatin was administered for six cycles; capecitabine and bevacizumab were continued until disease progression or unacceptable toxicity occurred. 5-Fluorouracil $\left(800 \mathrm{mg} / \mathrm{m}^{2} /\right.$ day as a continuous intravenous infusion on days $1-5$ every 3 weeks) was administered instead of capecitabine to patients unable to take oral medications. Treatments given after disease progression were recorded.

\section{Assessments}

Tumor assessments (magnetic resonance imaging and/or computed tomography) were performed within 21 days before randomization and were repeated every 6 weeks for the first year after randomization and every 12 weeks 
thereafter until disease progression. Survival status was assessed every 3 months after completion of study treatment.

Overall survival, the primary study endpoint, was defined as the time between randomization and death irrespective of cause. Progression-free survival was a secondary endpoint, defined as the time between randomization and first documented disease progression event or death.

\section{Statistical analysis}

The data cutoff date for the primary analysis was November 2009, after 517 overall survival events had occurred [4]. AVAGAST was completed in September 2013; data from this later cutoff were used in the present analysis. All analyses were performed in patients assigned to the placebo plus chemotherapy arm (intention-to-treat population). The present analyses were not previously planned in the study protocol and are exploratory in nature.

Participating countries were divided into four regions: USA and western Europe (Australia, Belgium, France, Germany, Italy, Spain, UK); eastern Europe (Russia) and South America (Brazil, Costa Rica, Peru); Korea and other Asian countries (Korea, China, Singapore, Taiwan); and Japan. Patient baseline characteristics and the proportion of patients who received chemotherapy after disease progression were compared among the four regions. Time-to-event endpoints were analyzed using the Kaplan-Meier method by region. Outcomes for USA/western Europe versus each of the other regions were compared using a Cox proportional hazards model and expressed as hazard ratios with $95 \%$ confidence intervals (CIs). A multivariate analysis of overall survival was also performed using Cox proportional hazards regression models with region and other prognostic variables as covariates, and the Wald chi-square test used to test differences between covariates.

\section{Results}

\section{Patient population}

A total of 387 patients were assigned to the placebo plus chemotherapy arm, of which 81 patients were enrolled from USA/western Europe, 118 patients from eastern Europe/ South America, 94 patients from Korea and other locations in Asia, and 94 patients from Japan.

Baseline characteristics by region are presented in Table 1. There were some differences between regions with respect to patient and tumor characteristics at baseline. An Eastern Cooperative Oncology Group (ECOG) performance status of 1 or 2 , the presence of liver metastases, and a maximum tumor size $\geq 40 \mathrm{~mm}$ were observed most frequently in patients enrolled from eastern Europe/South America and least often in patients from Japan. Liver and peritoneal metastases were each present in approximately $30-40 \%$ of patients in patients from USA/western Europe and eastern Europe/South America, whereas in Asian countries liver metastases were documented in $25-30 \%$ of patients and peritoneal metastases in $50-55 \%$ of patients.

\section{Post-progression chemotherapy}

A summary of chemotherapeutic agents given after disease progression is provided in Table 2. Subsequent chemotherapy after disease progression was given to 17 patients (14\%) enrolled from eastern Europe/South America, 30 (37\%) from USA/western Europe, 57 (61\%) from Korea and other Asia locations, and 72 (77\%) from Japan.

\section{Overall survival and progression-free survival}

At the cutoff date, the median duration of follow-up in the placebo plus chemotherapy arm was 9.7 months (range, $0.1-54.5$ months). A summary of efficacy by region is presented in Table 3. In the placebo plus chemotherapy arm, a total of 348 patients $(90 \%)$ had died. The median duration of overall survival was 7.3 months (95\% CI, 6.4-8.7) in eastern Europe/South America, 9.1 months (95\% CI, 6.9-14.4) in USA/western Europe, 11.6 months (95\% CI, 9.1-15.6) in Korea and other Asia, and 14.1 months (95\% CI, 10.9-17.6) in Japan. Kaplan-Meier curves for overall survival showed that the prognosis of patients in eastern Europe/South America tended to be worse than in other regions (Fig. 1a). The hazard ratios for overall survival for each region when compared against USA/western Europe were 1.47 (95\% CI, 1.09-1.99) for eastern Europe/South America, 0.91 (95\% CI, 0.67-1.25) for Korea and other Asia, and 0.87 (95\% CI, 0.64-1.19) for Japan. After adjusting for key prognostic factors (Table 4), the hazard ratios for overall survival for each region when compared against USA/western Europe showed little change [1.52 (95\% CI, 1.08-2.14) for eastern Europe/ South America, 0.82 (95\% CI, 0.57-1.18) for Korea and other Asia, and 0.81 (95\% CI, 0.57-1.14) for Japan].

In the placebo plus chemotherapy arm, a total of 371 patients (96\%) had progression-free survival events. Median progression-free survival by region was 4.4 months $(95 \% \mathrm{CI}$, 4.0-5.4) in eastern Europe/South America, 4.4 months (95\% CI, 4.0-5.7) in USA/western Europe, 5.6 months (95\% CI, 4.8-6.5) in Korea and other Asia, and 5.7 months (95\% CI, 5.1-7.0) in Japan. Kaplan-Meier curves of progression-free survival by region indicated that the prognosis of patients in eastern Europe/South America tended to be worse than in other regions (Fig. 1b). The hazard ratios for progressionfree survival for each region compared against USA/western Europe were 1.19 (95\% CI, 0.89-1.59) for eastern Europe/ 
Table 1 Baseline characteristics by region (placebo plus chemotherapy arm)

\begin{tabular}{|c|c|c|c|c|c|}
\hline Characteristic & & $\begin{array}{l}\text { USA/western } \\
\text { Europe }(n=81)\end{array}$ & $\begin{array}{l}\text { Eastern Europe/South } \\
\text { America }(n=118)\end{array}$ & $\begin{array}{l}\text { Korea and other } \\
\text { Asia }(n=94)\end{array}$ & Japan $(n=94)$ \\
\hline \multirow[t]{2}{*}{ Sex } & Male & $52(64)$ & $80(68)$ & $63(67)$ & $63(67)$ \\
\hline & Female & $29(36)$ & $38(32)$ & $31(33)$ & $31(33)$ \\
\hline \multirow[t]{2}{*}{ Age (years) } & $<65$ & $49(60)$ & $92(78)$ & $75(80)$ & $62(66)$ \\
\hline & $\geq 65$ & $32(40)$ & $26(22)$ & $19(20)$ & $32(34)$ \\
\hline \multirow[t]{2}{*}{ ECOG performance status } & 0 & $42(52)$ & $28(24)$ & $36(38)$ & $62(66)$ \\
\hline & $\geq 1$ & $39(48)$ & $90(76)$ & $58(62)$ & $32(34)$ \\
\hline \multirow[t]{2}{*}{ Primary site } & Stomach & $52(64)$ & $107(91)$ & $91(97)$ & $88(94)$ \\
\hline & Gastroesophageal junction & $29(36)$ & $11(9)$ & $3(3)$ & $6(6)$ \\
\hline \multirow[t]{2}{*}{ Disease status } & Locally advanced & $4(5)$ & $4(3)$ & 0 & $1(1)$ \\
\hline & Metastatic & $77(95)$ & $114(97)$ & $94(100)$ & $93(99)$ \\
\hline \multirow[t]{2}{*}{ Liver metastasis } & Yes & $27(34)$ & $51(43)$ & $25(27)$ & $23(24)$ \\
\hline & No & $53(66)$ & $67(57)$ & $69(73)$ & $71(76)$ \\
\hline \multirow[t]{2}{*}{ Number of metastatic sites } & $>1$ & $45(57)$ & $80(70)$ & $63(67)$ & $59(63)$ \\
\hline & $\leq 1$ & $34(43)$ & $35(30)$ & $31(33)$ & $35(37)$ \\
\hline \multirow[t]{2}{*}{ Histological type $^{\mathrm{a}}$} & Intestinal & $39(48)$ & $46(39)$ & $28(30)$ & $22(23)$ \\
\hline & Diffuse/mixed & $40(49)$ & $68(58)$ & $52(55)$ & $72(77)$ \\
\hline \multirow[t]{2}{*}{ Prior gastrectomy } & Yes & $16(20)$ & $32(27)$ & $28(30)$ & $31(33)$ \\
\hline & No & $65(80)$ & $86(73)$ & $66(70)$ & $63(67)$ \\
\hline \multirow[t]{2}{*}{ Prior (neo)adjuvant chemotherapy } & Yes & $9(11)$ & $3(3)$ & $10(11)$ & $8(9)$ \\
\hline & No & $72(89)$ & $115(97)$ & $84(89)$ & $86(91)$ \\
\hline \multirow[t]{3}{*}{ Disease measurability (tumor size) ${ }^{\mathrm{b}}$} & Not measurable & $16(20)$ & $18(15)$ & $27(29)$ & $29(31)$ \\
\hline & Measurable $(<40 \mathrm{~mm})$ & $39(49)$ & $47(40)$ & $48(51)$ & $47(50)$ \\
\hline & Measurable $(\geq 40 \mathrm{~mm})$ & $25(31)$ & $53(45)$ & $19(20)$ & 18 (19) \\
\hline \multirow[t]{2}{*}{ Peritoneal metastasis } & Yes & $24(30)$ & $47(40)$ & $49(52)$ & $52(55)$ \\
\hline & No & $57(70)$ & $71(60)$ & $45(48)$ & $42(45)$ \\
\hline \multirow[t]{2}{*}{ Bone metastasis } & Present & $4(5)$ & $4(3)$ & $3(3)$ & $5(5)$ \\
\hline & Not present & $76(95)$ & $114(97)$ & $91(97)$ & $89(95)$ \\
\hline
\end{tabular}

Data are expressed as $n(\%)$

ECOG Eastern Cooperative Oncology Group

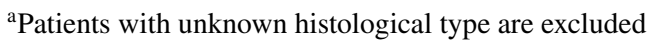

${ }^{\mathrm{b}}$ One patient from USA/western Europe had a measurable tumour of unknown size

Table 2 Post-progression chemotherapy for gastric cancer (placebo plus chemotherapy arm)

\begin{tabular}{lllll}
\hline Treatment & $\begin{array}{l}\text { USA/western } \\
\text { Europe }(n=81)\end{array}$ & $\begin{array}{l}\text { Eastern Europe/South } \\
\text { America }(n=118)\end{array}$ & $\begin{array}{l}\text { Korea and other } \\
\text { Asia }(n=94)\end{array}$ & Japan $(n=94)$ \\
\hline Total & $30(37)$ & $17(14)$ & $57(61)$ & $72(77)$ \\
Paclitaxel & 3 & 2 & 15 & 52 \\
Docetaxel & 12 & 2 & 24 & 13 \\
Irinotecan & 10 & 7 & 22 & 32 \\
5-Fluorouracil & 14 & 6 & 32 & 18 \\
S-1 & 0 & 0 & 9 & 14 \\
Capecitabine & 4 & 2 & 2 & 0 \\
Methotrexate & 0 & 0 & 2 & 12 \\
Folinic acid & 8 & 5 & 26 & 5 \\
Cisplatin & 2 & 3 & 10 & 7 \\
Oxaliplatin & 2 & 2 & 17 & 3 \\
\hline
\end{tabular}

Data are expressed as $n(\%)$ or $n$ 
Table 3 Efficacy outcomes by region (placebo plus chemotherapy arm)

\begin{tabular}{|c|c|c|c|}
\hline Region & $\begin{array}{l}\text { Number } \\
\text { of events }\end{array}$ & Median, months (95\% CI) & Hazard ratio $^{\mathrm{a}}(95 \% \mathrm{CI})$ \\
\hline \multicolumn{4}{|l|}{ Overall survival } \\
\hline USA/western Europe $(n=81)$ & 72 & $9.1(6.9-14.4)$ & - \\
\hline Eastern Europe/South America $(n=118)$ & 105 & $7.3(6.4-8.7)$ & $1.47(1.09-1.99)$ \\
\hline Korea and other Asia $(n=94)$ & 84 & $11.6(9.1-15.6)$ & $0.91(0.67-1.25)$ \\
\hline Japan $(n=94)$ & 87 & $14.1(10.9-17.6)$ & $0.87(0.64-1.19)$ \\
\hline \multicolumn{4}{|l|}{ Progression-free survival } \\
\hline USA/western Europe $(n=81)$ & 75 & $4.4(4.0-5.7)$ & - \\
\hline Eastern Europe/South America $(n=118)$ & 111 & $4.4(4.0-5.4)$ & $1.19(0.89-1.59)$ \\
\hline Korea and other Asia $(n=94)$ & 93 & $5.6(4.8-6.5)$ & $1.01(0.74-1.37)$ \\
\hline Japan $(n=94)$ & 92 & $5.7(5.1-7.0)$ & $0.96(0.71-1.31)$ \\
\hline
\end{tabular}

South America, 1.01 (95\% CI, 0.74-1.37) for Korea, and other Asia and 0.96 (95\% CI, 0.71-1.31) for Japan.

\section{Discussion}

The AVAGAST trial was designed to investigate the efficacy of adding a targeted agent - bevacizumab - to standard first-line chemotherapy for patients with advanced gastric cancer. Pre-planned subgroup analyses revealed marked differences between regions in overall survival, estimates that were viewed as robust because $60-70 \%$ of patients had died at the time of analysis [4]. The present set of exploratory analyses was performed to better understand the reasons for the regional differences observed in the AVAGAST study.

In our analyses, we observed that patients enrolled in eastern Europe/South America had the shortest median overall survival (7.3 months), followed by patients from USA/western Europe (9.1 months), with patients from both Asian regions showing the longest overall survival times (11.6-14.1 months). The same regional ranking was apparent in other study parameters, i.e. some baseline characteristics and the use of post-progression chemotherapy. We suggest that these differences may have contributed to the regional differences in survival outcomes.

In AVAGAST, the use of further lines of chemotherapy after disease progression was lowest in eastern Europe/ South America (14\% of patients), followed by USA/western Europe (37\%), with the highest usage evident in Korea $(61 \%)$ and Japan (77\%). The inverse relationship between the use of post-progression chemotherapy and overall survival suggests that this was a likely contributing factor to the different survival outcomes between regions. Similar observations have been made in the RAINBOW trial, where uptake of chemotherapy after discontinuation of study treatment was also higher in patients enrolled from Asian centers $(67 \%$ vs. 37\% of patients from other regions), along with improved overall survival (median, 10.5 months in Asia vs. 5.9 months in other regions) [8].

A possible reason for the differential uptake of secondline therapy is that there was no clear evidence to support the use of chemotherapy after disease progression yet there was considerable risk of toxicity. In the intervening years, several phase III randomised trials have demonstrated that secondline chemotherapeutic [9-12] or targeted agents [8, 13] significantly improve overall survival in patients with gastroesophageal cancer compared with best supportive care/ active symptom control. These trials have established the role of second-line therapy in patients with gastroesophageal cancer, a practice that is now endorsed in major European [14] and US [15] clinical practice guidelines. Other possible reasons to explain the differential use of post-progression chemotherapy may include differences in health insurance between countries. Few drugs are reimbursed for second and later lines of therapy in patients with gastric cancer in eastern Europe and South America, whereas more drugs are reimbursed in Japan. Not all patients are physically fit enough to be offered second-line therapy. In our analysis of patients' baseline characteristics, the likelihood of a poor ECOG performance status was greatest in eastern Europe/ South America and lowest in the Asian regions, which may also have influenced the choice of therapy.

We also identified differences in baseline tumor characteristics among regions. Patients in eastern Europe/South America were more likely to have liver metastases and measurable disease $\geq 40 \mathrm{~mm}$ at baseline than patients enrolled from other regions; patients from both Asian regions had the lowest rates for both parameters. Conversely, peritoneally limited disease was more common in Asian countries. These findings are consistent with an earlier diagnosis of gastric cancer and are probably linked to the screening programs that are in place in some Asian countries. Japan and Korea 
Fig. 1 Kaplan-Meier curves by region of (a) overall survival and (b) progression-free survival. Data are for the placebo plus chemotherapy arm only a

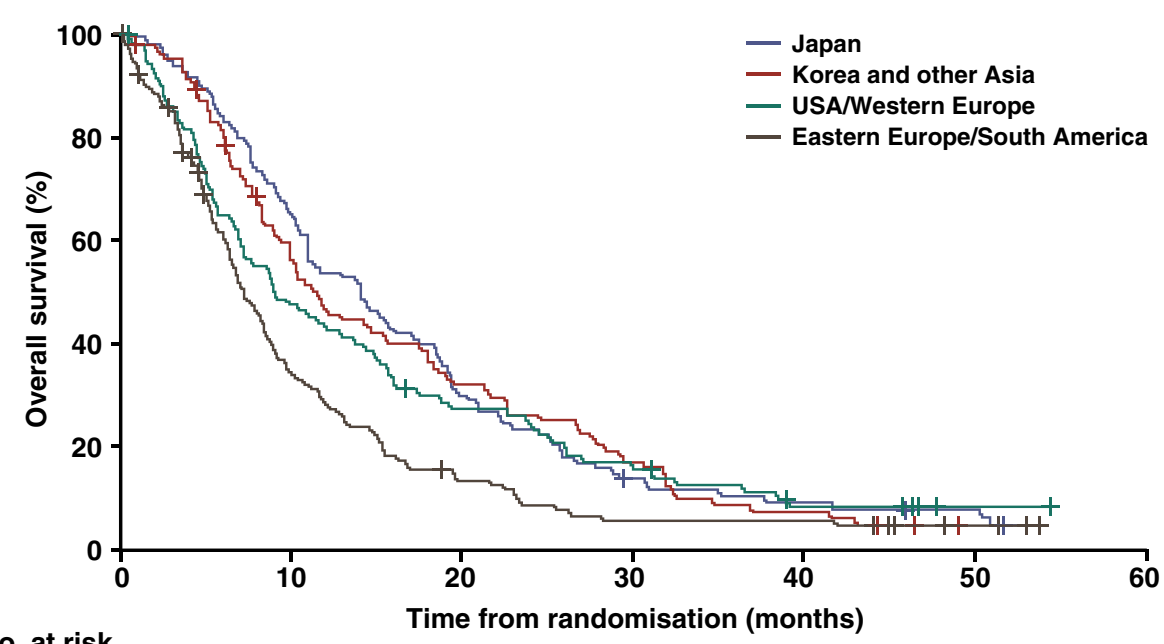

No. at risk

\begin{tabular}{cccccccccccccc}
\hline & 118 & 75 & 38 & 24 & 14 & 9 & 6 & 6 & 6 & 3 & 2 & 0 & 0 \\
\hline & 81 & 60 & 38 & 30 & 21 & 17 & 12 & 9 & 5 & 5 & 1 & 0 & 0 \\
-94 & 80 & 49 & 37 & 28 & 22 & 15 & 7 & 6 & 3 & 0 & 0 & 0 \\
\hline & 94 & 83 & 61 & 43 & 28 & 21 & 12 & 10 & 8 & 7 & 5 & 0 & 0
\end{tabular}

b

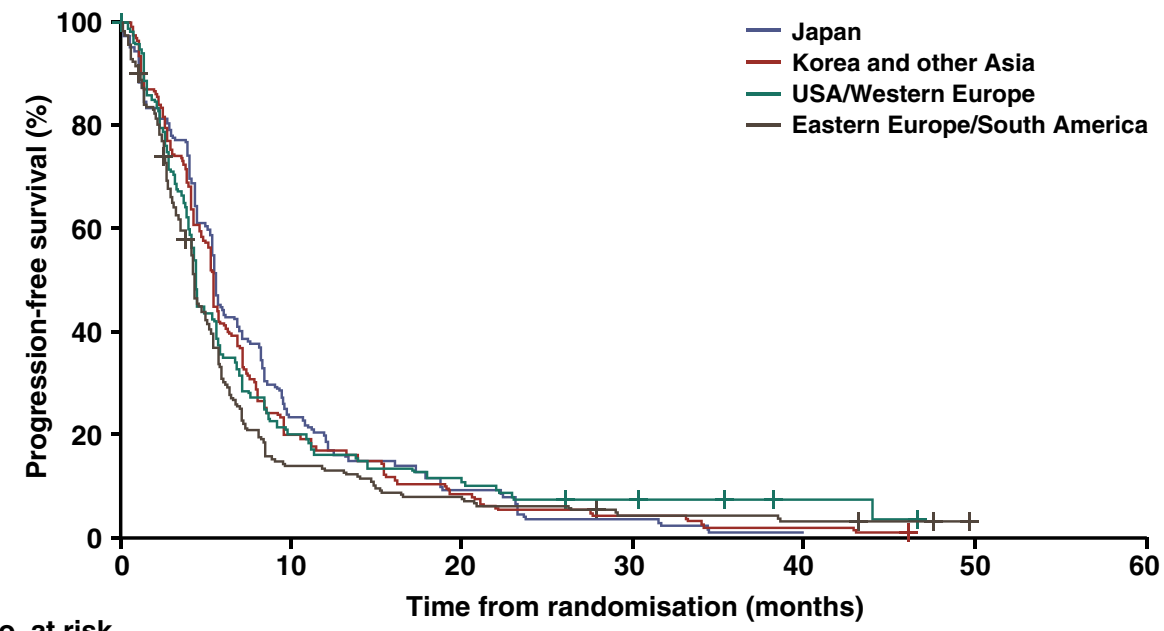

No. at risk

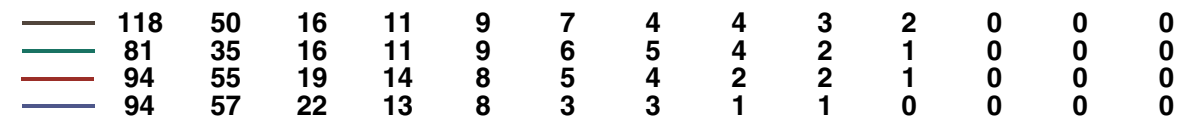

have ongoing nationwide screening programs, both of which were in place before AVAGAST started [16-19]. Further, Taiwan has a screening program for a high-risk population (on Matzu Island) [18, 19]. A secondary prevention program (i.e., upper gastrointestinal endoscopy for all symptomatic cases) in patients aged $\geq 40$ years was also established in Chile in 2006 [20]. Other countries and regions with a lower risk of gastric cancer do not have screening programs because they are not likely to be cost effective. In our analysis, earlier detection of primary tumors in countries with screening programs may have led to earlier identification of metastatic disease and an apparently longer overall survival (i.e., lead-time bias) versus regions without screening programs.

Molecular heterogeneity may also underpin the findings from our study, although gene expression profiling was not performed in AVAGAST. The Cancer Genome Atlas Research Network reported differences in pathwaylevel gene expression between patients from eastern Asia compared with patients from other regions [21]. Another recent study revealed that tumors from Asian and non-Asian patients exhibited distinct differences in gene signatures 
Table 4 Cox proportional hazards analysis of overall survival (placebo plus chemotherapy arm)

\begin{tabular}{llr}
\hline Covariate & Hazard ratio (95\% CI) & $p$ value \\
\hline Japan vs. USA/western Europe & $0.81(0.57-1.14)$ & 0.2270 \\
Korea and other Asia vs. USA/western Europe & $0.82(0.57-1.18)$ & 0.2936 \\
Eastern Europe/South America vs. USA/western Europe & $1.52(1.10-2.14)$ & 0.0170 \\
Sex (female vs. male) & $1.01(0.80-1.28)$ & 0.9275 \\
Age (<65 vs. $\geq 65$ years) & $0.90(0.70-1.16)$ & 0.4050 \\
ECOG performance status (0 vs. $\geq 1)$ & $0.73(0.57-0.93)$ & 0.0116 \\
Primary site (gastroesophageal junction vs. stomach) & $1.11(0.77-1.60)$ & 0.5754 \\
Disease status (locally advanced vs. metastatic) & $2.81(1.33-5.92)$ & 0.0067 \\
Liver metastases (no vs. yes) & $0.71(0.53-0.94)$ & 0.0161 \\
Histological type (diffuse vs. mixed) & $0.98(0.62-1.57)$ & 0.9434 \\
Histological type (intestinal vs. mixed) & $0.75(0.47-1.22)$ & 0.2473 \\
Prior gastrectomy (no vs. yes) & $1.61(1.23-2.11)$ & 0.0006 \\
Prior (neo)adjuvant therapy (no vs. yes) & $0.74(0.49-1.12)$ & 0.1510 \\
Tumor size (<40 mm vs. not measurable) & $1.17(0.86-1.58)$ & 0.3251 \\
Tumor size ( $\geq 40$ mm vs. not measurable) & $1.04(0.74-1.46)$ & 0.8259 \\
Bone metastases (no vs. yes) & $0.45(0.25-0.78)$ & 0.0050 \\
Peritoneal metastases (no vs. yes) & $0.55(0.42-0.73)$ & $<0.0001$ \\
Number of metastatic sites $(>1$ vs. $\leq 1)$ & $0.96(0.73-1.26)$ & 0.7584 \\
\hline
\end{tabular}

ECOG Eastern Cooperative Oncology Group related to inflammation and immunity, with T-cell pathways being preferentially associated with gastric cancers in nonAsian patients compared with Asian patients [22]. Further, the Asian Cancer Research Group used gene expression data to identify four distinct molecular subtypes that were associated with disease progression and prognosis [23]. Notably, the proportions of patients with these tumor subtypes varied according to geographic region [23]. It is likely that such studies will provide further insight into tumor characteristics and their implications for prognosis.

It is interesting to note that the overall survival of patients with advanced gastric cancer in clinical trials performed in the 1990s was relatively similar among regions (Table 5). It seems unlikely that major changes in biological characteristics of gastric tumors have developed in the past decade to explain the regional differences in AVAGAST. Rather, we suggest that differential changes in clinical practice (i.e., improved early diagnosis in high-risk countries, use of second-line therapy) may have had a greater effect than biological differences. It is also interesting to note that data from more recent studies (Table 5) show gradual improvements in overall survival in non-Asian regions and a trend toward convergence of survival times.

The analyses reported in the present paper were exploratory in nature and hypothesis generating only but may assist with the design of future international trials in advanced gastric cancer. We believe that there are no regional differences in drug efficacy in general. If regional differences related to other factors exist, they should be considered and kept to a minimum by appropriate study design, not only with regard to stratification factors but also with the statistical design based on the assumed overall survival of the patient population included in the study.

In conclusion, regional differences in the healthcare environment (i.e., use of second-line chemotherapy and screening programs) may have contributed to the differences in prognosis observed in the AVAGAST study. As second-line therapy for metastatic disease and screening programs in high-risk populations become more widely used, differences in outcomes in patients with advanced gastric cancer may diminish among regions.

Acknowledgements We thank the patients and their family members, investigators, and staff from the medical institutions that participated in the trial. We dedicate this manuscript to Dr. Hiroya Takiuchi (Osaka Medical College Hospital, Osaka, Japan), an investigator involved in this trial, who sadly passed away before he could see the manuscript submitted.

\section{Compliance with ethical standards}

Ethical standards All procedures followed were in accordance with the ethical standards of the responsible committee on human experimentation (institutional and national) and with the Helsinki Declaration of 1964 and later versions.

Informed consent Informed consent or substitute for it was obtained from all patients for being included in the study.

Funding Financial support for this research was provided by Genentech, F Hoffmann-La Roche, and Chugai Pharmaceutical Co. Ltd. Fuminori Shindo (Chugai Pharmaceutical Co., Ltd.) contributed to study operation and statistical analysis. Kensuke Kuniya (Chugai 
Table 5 Overall survival in phase III trials of first-line platinum/fluoropyrimidine-based regimens in advanced gastric cancer

\begin{tabular}{|c|c|c|c|c|c|}
\hline References & Region/country & Enrollment period & Treatment & No. of patients & $\begin{array}{l}\text { Median overall } \\
\text { survival, months }\end{array}$ \\
\hline Kim et al. [24] & Korea & 1986-1990 & FP & 103 & 8.5 \\
\hline Vanhoefer et al. [25] & Europe & $1991-1995$ & $\mathrm{FP}$ & 134 & 7.2 \\
\hline Ohtsu et al. [26] & Japan & 1992-1997 & FP & 105 & 7.1 \\
\hline Van Cutsem et al. [27] & International & 1999-2003 & FP & 230 & 8.6 \\
\hline Dank et al. [28] & International & 2000-2002 & FP & 165 & 8.7 \\
\hline \multirow[t]{4}{*}{ Cunningham et al. [29] } & \multirow[t]{4}{*}{ UK/Australia } & \multirow[t]{4}{*}{ 2000-2005 } & $\mathrm{EPF}$ & 263 & 9.9 \\
\hline & & & EPC & 250 & 9.9 \\
\hline & & & EOF & 245 & 9.3 \\
\hline & & & EOC & 244 & 11.2 \\
\hline Koizumi et al. [30] & Japan & 2002-2004 & $\mathrm{SP}$ & 148 & 13.0 \\
\hline \multirow[t]{2}{*}{ Kang et al. [31] } & \multirow[t]{2}{*}{ International } & \multirow[t]{2}{*}{ 2003-2005 } & $\mathrm{FP}$ & 156 & 8.9 \\
\hline & & & $\mathrm{CP}$ & 160 & 10.4 \\
\hline \multirow[t]{2}{*}{ Ajani et al. [32] } & \multirow{2}{*}{$\begin{array}{l}\text { USA/Europe/South } \\
\text { America }\end{array}$} & \multirow[t]{2}{*}{$2005-2007$} & SP & 527 & 8.6 \\
\hline & & & FP & 526 & 7.9 \\
\hline Ohtsu et al. [4] & International & $2007-2008$ & $\mathrm{CP}$ & 387 & 10.1 \\
\hline Lordick et al. [33] & International & 2008-2010 & $\mathrm{CP}$ & 455 & 10.7 \\
\hline Waddell et al. [34] & UK & 2008-2011 & EOC & 275 & 11.3 \\
\hline Kim et al. [35] & Korea & 2009-2012 & $\mathrm{CP}$ & 124 & 11.5 \\
\hline Shen et al. [36] & China & 2009-2010 & $\mathrm{CP}$ & 102 & 11.4 \\
\hline \multirow[t]{2}{*}{ Yamada et al. [37] } & \multirow[t]{2}{*}{ Japan } & \multirow[t]{2}{*}{ 2010-2011 } & SP & 324 & 13.1 \\
\hline & & & $\mathrm{SO}$ & 318 & 14.1 \\
\hline
\end{tabular}

Only data for the platinum/fluoropyrimidine-containing study arms are shown

$C$ capecitabine, $E$ epirubicin, $F$ 5-fluorouracil, $O$ oxaliplatin, $P$ cisplatin, $S$ S-1

Pharmaceutical Co., Ltd.) supported manuscript writing. We thank Harriet Lamb of Miller Medical Communications, who provided writing services on behalf of Chugai Pharmaceutical Co. Ltd.

Conflict of interest Akira Sawaki has received honoraria from Novartis, Pfizer, and Bayer. Yasuhide Yamada has received honoraria from Chugai Pharmaceutical Co. Ltd, Taiho, and Yakult. Kensei Yamaguchi has received honoraria from Chugai Pharmaceutical Co. Ltd., Merck, Takeda, and Eli Lilly, and declares another relationship with Taiho. Tomohiro Nishina has received honoraria from Chugai Pharmaceutical Co. Ltd. Taroh Satoh has received honoraria from Chugai Pharmaceutical Co. Ltd., Merck-Serono, Bristol-Myers Squibb, and Eli Lilly, performed consulting or advisory roles for Chugai Pharmaceutical Co. Ltd., Merck-Serono, Bayer, Eli Lilly, Ono, and DaiichiSankyo, and received research funding from Chugai Pharmaceutical Co. Ltd., Ono, and Yakult Honsha. Narikazu Boku has received honoraria from Chugai Pharmaceutical Co. Ltd. Yoshito Komatsu has received honoraria from Chugai Pharmaceutical Co. Ltd., Taiho, Yakult, and Eli Lilly, and received research funding from Chugai Pharmaceutical Co. Ltd., Taiho, Eli Lilly, Ono, Merck, and Merck, Sharpe \& Dohme. Yasuo Hamamoto has received honoraria from Chugai Pharmaceutical Co. Ltd. Shigehira Saji has received honoraria and research funding from Chugai Pharmaceutical Co. Ltd. Manish A. Shah has received research funding from Berg Pharma, Sanofi Aventis, and Roche. Eric Van Cutsem has received research funding from Amgen, Bayer, Boehringer, Celgene, Ipsen, Lilly, Merck, Novartis, Roche, and Sanofi. Yoon-Koo Kang has received honoraria and research funding, and performed consulting or advisory roles for Roche. Junko Iwasaki, Hiroshi Kuriki, Wataru Ohtsuka are employees of Chugai Pharmaceu- tical Co. Ltd. Hiroshi Kuriki owns stock in Chugai Pharmaceutical Co. Ltd. Toshihiko Doi, Keisho Chin, Yasushi Omuro, Wasaburo Koizumi, and Atsushi Ohtsu declare that they have no conflicts of interest.

Open Access This article is distributed under the terms of the Creative Commons Attribution 4.0 International License (http://creativecommons.org/licenses/by/4.0/), which permits unrestricted use, distribution, and reproduction in any medium, provided you give appropriate credit to the original author(s) and the source, provide a link to the Creative Commons license, and indicate if changes were made.

\section{References}

1. Ferlay J, Soerjomataram I, Ervik M, Dikshit R, Eser S, Mathers C, et al. GLOBOCAN 2012 v. 1.0, Cancer Incidence and Mortality Worldwide: IARC CancerBase no. 11 (Internet). Lyon, France: International Agency for Research on Cancer. http://globocan.iarc. fr. Accessed 22 May 2015.

2. Pieters A, Laurent S, Dero I, Van Damme N, Peeters M. The role of oral fluoropyrimidines in the treatment of advanced gastric cancer. Acta Gastroenterol Belg. 2008;71:361-6.

3. Buas MF, Vaughan TL. Epidemiology and risk factors for gastroesophageal junction tumors: understanding the rising incidence of this disease. Semin Radiat Oncol. 2013;23:3-9.

4. Ohtsu A, Shah MA, Van Cutsem E, Rha SY, Sawaki A, Park $\mathrm{SR}$, et al. Bevacizumab in combination with chemotherapy 
as first-line therapy in advanced gastric cancer: a randomized, double-blind, placebo-controlled phase III study. J Clin Oncol. 2011;29:3968-76.

5. Van Cutsem E, de Haas S, Kang YK, Ohtsu A, Tebbutt NC, Ming $\mathrm{XuJ}$, et al. Bevacizumab in combination with chemotherapy as first-line therapy in advanced gastric cancer: a biomarker evaluation from the AVAGAST randomized phase III trial. J Clin Oncol. 2012;30:2119-27.

6. Hacker UT, Escalona-Espinosa L, Consalvo N, Goede V, Schiffmann L, Scherer SJ, et al. Evaluation of angiopoietin-2 as a biomarker in gastric cancer: results from the randomised phase III AVAGAST trial. Br J Cancer. 2016;114:855-62.

7. Therasse P, Arbuck SG, Eisenhauer EA, Wanders J, Kaplan RS, Rubinstein L, et al. New guidelines to evaluate the response to treatment in solid tumors: European Organization for Research and Treatment of Cancer, National Cancer Institute of the United States, National Cancer Institute of Canada. J Natl Cancer Inst. 2000;92:205-16.

8. Wilke H, Muro K, Van Cutsem E, Oh SC, Bodoky G, Shimada Y, et al. Ramucirumab plus paclitaxel versus placebo plus paclitaxel in patients with previously treated advanced gastric or gastrooesophageal junction adenocarcinoma (RAINBOW): a doubleblind, randomised phase 3 trial. Lancet Oncol. 2014;15:1224-35.

9. Thuss-Patience PC, Kretzschmar A, Bichev D, Deist T, Hinke A, Breithaupt K, et al. Survival advantage for irinotecan versus best supportive care as second-line chemotherapy in gastric cancer: a randomised phase III study of the Arbeitsgemeinschaft Internistische Onkologie (AIO). Eur J Cancer. 2011;47:2306-14.

10. Ford HE, Marshall A, Bridgewater JA, Janowitz T, Coxon FY, Wadsley J, et al. Docetaxel versus active symptom control for refractory oesophagogastric adenocarcinoma (COUGAR-02): an open-label, phase 3 randomised controlled trial. Lancet Oncol. 2014;15:78-86.

11. Kang JH, Lee SI, Lim do H, Park KW, Oh SY, Kwon HC, et al. Salvage chemotherapy for pretreated gastric cancer: a randomized phase III trial comparing chemotherapy plus best supportive care with best supportive care alone. J Clin Oncol. 2012;30:1513-8.

12. Hironaka S, Ueda S, Yasui H, Nishina T, Tsuda M, Tsumura T, et al. Randomized, open-label, phase III study comparing irinotecan with paclitaxel in patients with advanced gastric cancer without severe peritoneal metastasis after failure of prior combination chemotherapy using fluoropyrimidine plus platinum: WJOG 4007 trial. J Clin Oncol. 2013;31:4438-44.

13. Fuchs CS, Tomasek J, Yong CJ, Dumitru F, Passalacqua R, Goswami C, et al. Ramucirumab monotherapy for previously treated advanced gastric or gastro-oesophageal junction adenocarcinoma (REGARD): an international, randomised, multicentre, placebocontrolled, phase 3 trial. Lancet. 2014;383:31-9.

14. Smyth EC, Verheij M, Allum W, Cunningham D, Cervantes A, Arnold D, ESMO Guidelines Committee. Gastric cancer: ESMO Clinical Practice Guidelines for diagnosis, treatment and followup. Ann Oncol. 2016;27(suppl 5):v38-49.

15. Ajani JA, D'Amico TA, Almhanna K, Bentrem DJ, Chao J, Das P, et al. Gastric Cancer, Version 3.2016. NCCN Clinical Practice Guidelines in Oncology. J Natl Compr Canc Netw. 2016;14:1286-312.

16. Yoo KY. Cancer control activities in the Republic of Korea. Jpn J Clin Oncol. 2008;38:327-33.

17. Sasako M, Inoue M, Lin JT, Khor C, Yang HK, Ohtsu A. Gastric Cancer Working Group report. Jpn J Clin Oncol. 2010;40(Suppl 1):i28-37.

18. IARC Helicobacter pylori Working Group. Helicobacter pylori eradication as a strategy for preventing gastric cancer. Lyon, France: International Agency for Research on Cancer 2014 (IARC Working Group Reports, No. 8). http://www.iarc.fr/en/ publications/pdfs-online/wrk/wrk8/index.phpv. Accessed 19 May 2015.

19. Leung WK, Wu MS, Kakugawa Y, Kim JJ, Yeoh KG, Goh KL, et al. Screening for gastric cancer in Asia: current evidence and practice. Lancet Oncol. 2008;9:279-87.

20. Calvo A, Galleguillos BJ, Baez S, Diaz A, Pruyas M, Nilsen EM, et al. Results of a population-based gastric cancer screening program conducted in Chile 1996-2008. Gastroenterology. 2011;140(Suppl 1):S-419 (abstract Su1161).

21. Cancer Genome Atlas Research Network. Comprehensive molecular characterization of gastric adenocarcinoma. Nature (Lond). 2014;513:202-9.

22. Lin SJ, Gagnon-Bartsch JA, Tan IB, Earle S, Ruff L, Pettinger K, et al. Signatures of tumour immunity distinguish Asian and nonAsian gastric adenocarcinomas. Gut. 2015;64:1721-31.

23. Cristescu R, Lee J, Nebozhyn M, Kim KM, Ting JC, Wong SS, et al. Molecular analysis of gastric cancer identifies subtypes associated with distinct clinical outcomes. Nat Med. 2015;21:449-56.

24. Kim NK, Park YS, Heo DS, Suh C, Kim SY, Park KC, et al. A phase III randomized study of 5-fluorouracil and cisplatin versus 5-fluorouracil, doxorubicin, and mitomycin $\mathrm{C}$ versus 5 -fluorouracil alone in the treatment of advanced gastric cancer. Cancer (Phila). 1993;71:3813-8.

25. Vanhoefer U, Rougier P, Wilke H, Ducreux MP, Lacave AJ, Van Cutsem E, et al. Final results of a randomized phase III trial of sequential high-dose methotrexate, fluorouracil, and doxorubicin versus etoposide, leucovorin, and fluorouracil versus infusional fluorouracil and cisplatin in advanced gastric cancer: a trial of the European Organization for Research and Treatment of Cancer Gastrointestinal Tract Cancer Cooperative Group. J Clin Oncol. 2000;18:2648-57.

26. Ohtsu A, Shimada Y, Shirao K, Boku N, Hyodo I, Saito H, et al. Randomized phase III trial of fluorouracil alone versus fluorouracil plus cisplatin versus uracil and tegafur plus mitomycin in patients with unresectable, advanced gastric cancer: the Japan Clinical Oncology Group Study (JCOG9205). J Clin Oncol. 2003;21:54-9.

27. Van Cutsem E, Moiseyenko VM, Tjulandin S, Majlis A, Constenla $\mathrm{M}$, Boni C, et al. Phase III study of docetaxel and cisplatin plus fluorouracil compared with cisplatin and fluorouracil as first-line therapy for advanced gastric cancer: a report of the V325 Study Group. J Clin Oncol. 2006;24:4991-7.

28. Dank M, Zaluski J, Barone C, Valvere V, Yalcin S, Peschel C, et al. Randomized phase III study comparing irinotecan combined with 5-fluorouracil and folinic acid to cisplatin combined with 5-fluorouracil in chemotherapy naive patients with advanced adenocarcinoma of the stomach or esophagogastric junction. Ann Oncol. 2008;19:1450-7.

29. Cunningham D, Starling N, Rao S, Iveson T, Nicolson M, Coxon $\mathrm{F}$, et al. Capecitabine and oxaliplatin for advanced esophagogastric cancer. N Engl J Med. 2008;358:36-46.

30. Koizumi W, Narahara H, Hara T, Takagane A, Akiya T, Takagi M, et al. S-1 plus cisplatin versus S-1 alone for first-line treatment of advanced gastric cancer (SPIRITS trial): a phase III trial. Lancet Oncol. 2008;9:215-21.

31. Kang YK, Kang WK, Shin DB, Chen J, Xiong J, Wang J, et al. Capecitabine/cisplatin versus 5-fluorouracil/cisplatin as first-line therapy in patients with advanced gastric cancer: a randomised phase III noninferiority trial. Ann Oncol. 2009;20:666-73.

32. Ajani JA, Rodriguez W, Bodoky G, Moiseyenko V, Lichinitser $\mathrm{M}$, Gorbunova V, et al. Multicenter phase III comparison of cisplatin/S-1 with cisplatin/infusional fluorouracil in advanced gastric or gastroesophageal adenocarcinoma study: the FLAGS trial. J Clin Oncol. 2010;28:1547-53. 
33. Lordick F, Kang YK, Chung HC, Salman P, Oh SC, Bodoky $\mathrm{G}$, et al. Capecitabine and cisplatin with or without cetuximab for patients with previously untreated advanced gastric cancer (EXPAND): a randomised, open-label phase 3 trial. Lancet Oncol. 2013;14:490-9.

34. Waddell T, Chau I, Cunningham D, Gonzalez D, Okines AF, Okines $\mathrm{C}$, et al. Epirubicin, oxaliplatin, and capecitabine with or without panitumumab for patients with previously untreated advanced oesophagogastric cancer (REAL3): a randomised, openlabel phase 3 trial. Lancet Oncol. 2013;14:481-9.

35. Kim ST, Kang JH, Lee J, Park SH, Park JO, Park YS, et al. Simvastatin plus capecitabine-cisplatin versus placebo plus capecitabine-cisplatin in patients with previously untreated advanced gastric cancer: a double-blind randomised phase 3 study. Eur J Cancer. 2014;50:2822-30.

36. Shen L, Li J, Xu J, Pan H, Dai G, Qin S, et al. Bevacizumab plus capecitabine and cisplatin in Chinese patients with inoperable locally advanced or metastatic gastric or gastroesophageal junction cancer: randomized, double-blind, phase III study (AVATAR study). Gastric Cancer. 2015;18:168-76.

37. Yamada Y, Higuchi K, Nishikawa K, Gotoh M, Fuse N, Sugimoto N, et al. Phase III study comparing oxaliplatin plus S-1 with cisplatin plus S-1 in chemotherapy-naïve patients with advanced gastric cancer. Ann Oncol. 2015;26:141-8. 